\title{
Social Support and Morality Among Community Dwelling Elders
}

\author{
*Heba Shafik Ibrahim ${ }^{1} \quad$ Ahlam Mahmoud Mohamed Ali ${ }^{2}$ \\ 1. Lecturer, Psychiatric Nursing and Mental Health Department, Faculty of Nursing, Damanhour University, \\ Egypt \\ 2.Lecturer, Community Health Nursing Department, Faculty of Nursing, Alexandria University, Egypt
}

\begin{abstract}
Social support prevents mental and psychological distress of elderly people. Elderly individuals are revered and respected by family and friends. Many moral values elderly people can acquired through their relations with their children, friends and relatives. This study aimed to investigate the relationship between social support and morality among community dwelling elders. The study followed a descriptive correlational research design. It was conducted on 240 elders, at Damanhour and Alexandria governorate elders' clubs. Multidimensional Scale of Perceived Social Support (MSPSS) and The Philadelphia Geriatric Center Morale Scale (PGCMS) scales were used to collect the data of this study. The results revealed that there is a significant relationship between elders perceived social support and their level of morality.It was concluded that, there is a significant relation between morals and multi-dimensions perceived social support among community dwelling elders. There is a significant relation between Sons/daughters, relative visits and having friends and multidimensional perceived social support and morality. Recommendations encompassed that increasing numbers of elders' clubs with sufficient financial support; will permit elders to engage in club activities. Family members should respect the elders' decisions, appreciate their personal achievements, as it will reflect that elders are still valued, wanted and useful; this will increase their feeling of satisfaction and enhance their morals. Elders must be encouraged to participate actively in the economic, political, social and cultural life of their societies.
\end{abstract}

Keywords: Social support, Morality, community dwelling elders

DOI: $10.7176 / \mathrm{JHMN} / 70-02$

Publication date: January $31^{\text {st }} 2020$

\section{Introduction:}

According to WHO, the population aged 60 and over is expected to increase from 600 million to an estimated 2 billion by 2050 (WHO, 2012a). ${ }^{(1)}$ In Egypt, it was reported that the relative number of elders aged 60 and more, was about 4.5 millions in 2008, 4.8 million in 2010 and $9 \%$ in 2015. It is expected that this number increases by $12 \%$ in $2030 .^{(2)}$

The perception of becoming old varies from one person to another. For some, it gives the elders free time to read, socialize, practice previous activities and being involved in a volunteer work or it may be the beginning of a new career and life. ${ }^{(3)}$ For others, it is the time for facing age associated losses, including the loss of job, health and loved ones. ${ }^{(4)}$ The list of losses suffered by elders can be infinite, but people should consider that the small losses can be as catastrophic as some major ones, and the multiplicity of later life losses may contribute to many psychological issues. ${ }^{(5)}$ Old age comes with the impairment of physical and spiritual power, thereby placing the elderly person in a very vulnerable position. Elders may also suffer from issues such as loneliness, depression, anxiety, and, ultimately physical and mental problems due to "automated" life that characterizes the modern world now; residence alone or with others in small homes, reduced number of children or children's immigration to other cities. Such concerns illustrate the need to pay attention to the elders age group, provide them with necessary support, examine and evaluate their needs in all aspects of life. One such dimension is social support received from family or friends. Moreover, levels of interaction and social support can affect satisfaction and general health of elders. ${ }^{(6)}$

Social support is defined in terms of social network characteristics such as assistance from family, friends, neighbors and other community members, to assist individuals coping with everyday life, and particularly in responses to critical situation. ${ }^{(7)}$

Social network and stay in close contact with family and friends in a form of providing or receiving help and support (helping others, family relations, and receiving help) are considered one of the main elements of successful aging. Social resources (support, significant relationships) are identified as factors that influence coping of the elderly people with life losses and stressors. ${ }^{(8)}$

In elderly populations; attached social networks with great levels of social support generally act as a protective factor for maintaining good health and quality of life in old age. ${ }^{(9)}$ A study of over 1200 communitydwelling older adults in Spain (2001) concluded that high emotional support was positively associated with physical and mental health of the elderly people. ${ }^{(10)}$ Also, McNicholas (2002) confirmed that social support, selfesteem, and optimism were all related positively to favorable health practices; and social support was related positively to self-esteem and optimism. ${ }^{(11)}$ 
As mentioned before; social support prevents mental and psychological distress of elders. No doubt that, Living with family members, including spouses and children and acquiring financial, emotional attention and support, help in creating feelings of love, care, self-esteem, and value among the elders, thus healthy life.

Social support definition falls into two categories; objective social support that shows what people have actually received or report to have received. The other is a subjective perception, that reflects the view and beliefs of a person about the available support, and which is more persistently and more powerfully related to health and well-being than are objective one. Elderly club membership was associated with perceived social support. ${ }^{(11)}$ In Thailand, elders clubs give members an opportunity for social interaction that consequently affects their social relationships and which ultimately influences the flow of resources to each member. ${ }^{(12)}$ Also, the friends of elders can accompany them in social activities more frequently than can their children or other relatives.

Social network can provide social companionship, instrumental aid, as well as emotional comfort to the elderly person; helping to release pressure, to reduce depressive feelings, and to buffer the harmful effect of stressful life events on health (Silverman et al, 2000). ${ }^{(13)}$

In Islamic culture, in which respect for the elders, especially parents, is of utmost importance; both male and female elders are revered by family and friends. ${ }^{(6)}$ A study done by Geest S (2002) indicating that elders should be respected and valued among their communities.(14). Respect is one of the moral values that unconditionally required for all. ${ }^{(15)}$ A descriptive definition of morality is referred to "certain codes of conduct put forward by a society or a group (such as a religion), or accepted by an individual for her own behavior". (16)

Morality is inherent in the psyche of every individual which is influenced by various internal personality characteristics and external social factors because itis also a social phenomenon. ${ }^{(17)}$ According to Borg $\mathrm{C}$ and Blomomqvist K (2006), 'Life satisfaction and morale scales measure more enduring and stable cognitions. ${ }^{(18)}$

Moral values are guiding principles of life. They are responsible for the all-round development of an individual. Values reflect ones personality, his attitude, behavior, his mission and vision. Values are the backbone of any personality, religion, society or a nation. It can bring in peace of mind, joyful environment, better quality of life, sustainability, harmony in the global society. ${ }^{(17)}$

Core human values such as honesty, sincerity, morality, humanity, non-violence are getting affected because of poverty, unsocialibility, caste system, gender inequality, ill treatment to child women and elders. ${ }^{(17,19)}$

Indians generally say that in their society children have long felt a deep social-moral obligation in their culture to care for elderly parents. According to these mores, adult children - especially sons and daughters-inlaw-live with and care for their elderly parents out of love, a deep respect for them, and a deep sense of moral. Even spiritually, duty to attempt to repay the inerasable debts they owe their parents for all the effort, expense, and affection their parents expended to produce and raise them. ${ }^{(19)}$ Being belonging to a family with social support can enhance the elders' moral values such as acceptance, dependability, cooperation, life satisfaction and happiness. ${ }^{(20)}$ It was reported that happiness as a moral value in old age can be acquired through high social support,which in turn reflected on the elders physical, psychological health and their quality of life. ${ }^{(6,21)}$

In elderly individuals, life satisfaction is a multidimensional issue that is influenced by objective and subjective characteristics, including cognitive function, emotional status, social support, physical condition, dependency, and sociodemographic variables. ${ }^{(22)}$

The professional nature of the nurse-client/ patient relationship is grounded in an ethic of caring. Nurse should be aware with issues that affect elders' health. ${ }^{(23,24)}$ Nurses play a significant role in promoting elders functional, physical, social engagement and mental wellness and providing high quality safe care through implementing group interventions, such as healthy aging classes, to help individuals to cope more effectively with the life events of elders and also educate the public regarding how to help elders to age successfully that can be achieved by high social support and high level of morals. ${ }^{(25,26)}$ In relation to this issue; this study aimed to investigate the relationship between social support and morality among community dwelling elders.

\section{Operational definition:}

Morality can be used alternatively with moral values in this study

\section{Aims of the study \\ The study is aimed to:}

- Assess social support level among community dwelling elders.

- Assess moral level among community dwelling elders.

- Investigate the relationship between social support and morality among community dwelling elders.

\section{Research questions:}

- What is the social support level among community dwelling elders?

- What is the morality level among community dwelling elders? 
- What is the relation between social support and morality among community dwelling elders?

\section{Materials\& Method \\ Materials \\ Research design:}

A descriptive correlational research design was followed in this study

Setting:

The study was carried out in two governmental elders' clubs in Alexandria namely, El Hayah we el Amal club and El Wafaa club, were chosen randomly and one club in Damanhour namely social club,this is the only club that provides these services for all population including elders in Damanhour governorate. These clubs are affiliated to the Ministry of Social Solidarity. They provide many recreational, religious, cultural and health care activities for elders such as trips, social parties and seminars in different areas, such as religious, cultural and health topics. Damanhour social club is providing services for all age groups including aging population.

\section{Subjects:}

All elders attending the above-mentioned clubs and fulfilling the following criteria were included in the study, aged 60years and more, able to communicate effectively and agree to participate in the study. The total number of the studied subjects was 240 elders. The sample size was estimate using Epi info 7 statistical program according to the following parameters; population size 640 , expected frequency $50 \%, 95 \%$ confidence level with $5 \%$ maximum error. The minimum sample size estimated to be 240 elders.

\section{Tools of data collection:}

In order to collect the necessary data for the study, the following tools were used.

Tool (I):-Elderly Bio-psycho-social characteristics structured interview schedule

It was developed by the researchers after reviewing recent literature to collect necessary data from the elders, to investigate certain items related to:

- Socio-demographic characteristics of the elderly such as age, sex, social status, level of education, occupation before retirement and income.

- Elders' medical history which included; types of chronic diseases affecting the elderly client, sensory problems and mobility level.

- Psycho-social factors such as widowhood, retirement, availability of social support network, frequency of family visits, availability of recreational activities, as well as practicing hobbies and things of interests.

\section{Tool II: Multidimensional Scale of Perceived Social Support (MSPSS)}

Multidimensional Scale of Perceived Social Support (MSPSS) was developed by Zimet et al (1988) ${ }^{(27)}$ It consists of 12 items that measure how much support a parent feels they get from family, friends and significant others. Respondents rate statements on a seven-pointLikert scale of 1 to 7 , with 1 indicating very strongly disagree and 7 indicating very strongly agree. Any mean total scale score ranging from 1 to 2.9 could be considered low support; a score of 3 to 5 could be considered moderate support; a score from 5.1 to 7 could be considered high support. Multidimensional Scale of Perceived Social Support (MSPSS) was shown to be reliable, Cronbach's alpha coefficient $(\alpha)$ was $(0.93)$.

\section{Tool III: The Philadelphia Geriatric Center Morale Scale (PGCMS)}

The Philadelphia Geriatric Center Morale Scale was developed by Lawton's (1975). ${ }^{(28)}$ It consists of 17 items which are answered by yes or No. the 17 items divided into 3 subscales; namely agitation, Attitude Toward Own Aging and Lonely-Dissatisfaction subscale. The total score ranging from 1 to 5 could be considered low moral; a score of 6 to 11 could be considered moderate moral; a score from 12 to 17 could be considered high moral. The Philadelphia Geriatric Center Morale Scale was shown to be reliable, Cronbach's alpha coefficient ( $\alpha$ ) was $(0.92)$

\section{Methods}

The study was conducted through the following phases;

Administrative process:

- An official letter was directed from the Faculty of Nursing to Directorate of elders' clubs in Alexandria \&Damanhourto obtain an approval for collecting the necessary data from the selected settings.

- Meetings were held with directors of the selected elders clubs to clarify the purpose of the study and to gain their cooperation during data collection.

Content validity:

- After reviewing the recent literatures tool I(The elderly Bio-psycho-social structured interview schedule) was developed by the researchers.

- Multidimensional Scale of Perceived Social Support (Tool II) and The Philadelphia Geriatric Center Morale Scale (Tool III), were translated into Arabic language by the researchers 
- A jury of five experts in the related fields of Psychiatric and Mental Health Nursing, Gerontological Nursing and Community Health Nursing examined the content validity of tool II and III. The required Pilot study modifications were carried out accordingly.

Before embarking on the actual study, a pilot study was carried out on 24elders from the community in order to ascertain the relevance, clarity and applicability of the tools, test wording of the questions, identify obstacles that may be faced during data collection and estimate the time required for interviewing the elders. Based on the obtained results, the necessary modifications were done.

Field work:

- Elders clubs' names in Alexandria were listed and two of them were chosen randomly. In Damanhour, this is the only club that provides these services for all population including elders.

- Each elderly person fulfilling the study criteriawas interviewed individuallyfor once after brief explanation of the aim of the study to collect required information related to 3 tools.

- The interview took approximately 20-30 minutes for each elderly person.

- $\quad$ Data were collected by the researchers over a period from $1^{\text {st }}$ March 2019 to $30^{\text {th }}$ May2019.

Ethical considerations: -

- Informed oral /written consent was obtained from all participants after providing an appropriate explanation about the purpose of the study and nature of the research. For illiterate elderly person witness written consent was obtained.

- The confidentiality and anonymity of individual responses, volunteer participation and right to refuse participating in the study were emphasized to the participants.

Statistical analysis:

- The collected data were coded and analyzed using PC with the International Business Machine - Statistical Package for Social Sciences (IBM-SPSS version 25) and tabulated frequency and percentages were calculated.

- Descriptive statistics measures, which including number, percentages, and averages, measures of dispersion and central tendency (Minimum, Maximum, Arithmetic mean ( $\overline{\mathbf{x}})$, Standard deviation (SD). Measures of association Chi-square test $\left(\mathrm{X}^{2}\right)$, Fisher Exact Test (FET).

- The level of significance selected for this study was $p$ value equal to or less than 0.05 .

\section{Results}

Table (1) represents the socio-demographic characteristics of the studied elders. Regarding their sex, more than half of the studied elderly were females $(58.8 \%)$. The majority of the studied elderly $(80.8 \%)$ were aged between 60 to less than 75 years, while more than one tenth (16.7\%) of them were aged 75 to less than 85 years, with a mean age $67.9 \pm 6.6$ years. As for the place of residence the studied subjects were had equal percent number $(50 \%)$ of both Alexandria and Damanhour cities.

Regarding elders' marital status, more than half $(52.5 \%)$ of them were married, while more than two fifth $(46.7 \%)$ of them were widow. As for their educational level, the table also shows that more than one third $(38.8 \%)$ of the studied elderly were illiterate, compared to one fifth $(20 \%)$ of them had university education.

In relation to elders' work before retirement, more than two fifth $(46.3 \%)$ of elderly were housewife and more than one quarter $(27.1 \%)$ of them were employee. Also, the majority of the studied elders $(94.2 \%)$ reported that their family income wasn'tenough for their needs. Regarding the source of income, nearly two thirds $(62.5 \%)$ of the studied elders their pension was the main source of their income followed by nearly one third $(31.7 \%)$ of their source of income related to their children help. 
Table (1) Distribution of the studied elders according to their socio-demographic characteristics.

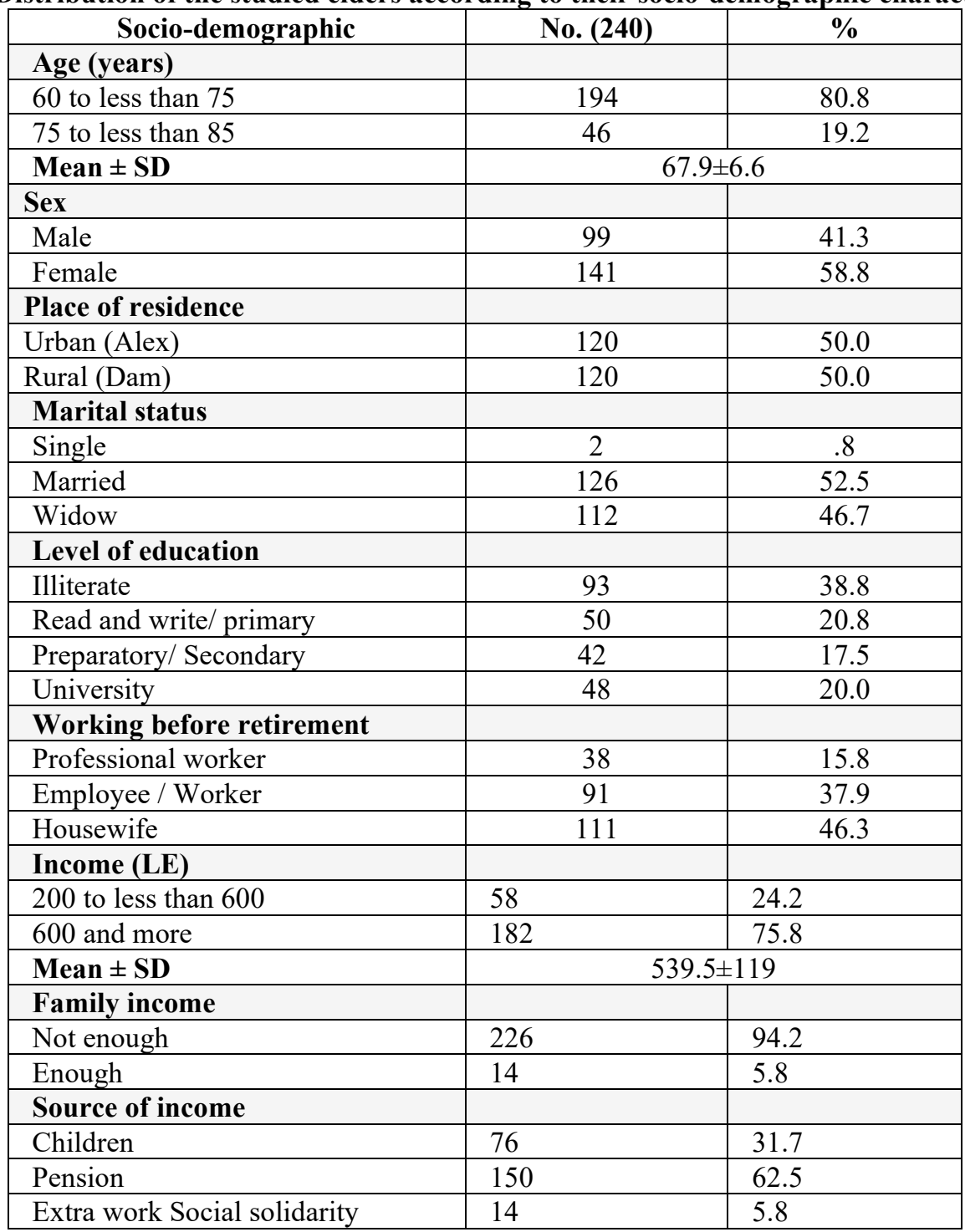

Table (2) presentsthe medical and general health status of the studied elders. It was observed that the majority $(85.8 \%)$ of the elders were suffering from health problems. Hypertension, DM, Rheumatoid diseases and Heart diseases were the most common problems that mentioned by the elders represented $(70 \%, 55.3 \%, 43.2 \%$ and $32.5 \%$ respectively).

As for sensory problems the same table reveals that one quarter $(25 \%)$ of the elders were suffering from hearing problems but they did not use hearing aids, compared to $(16.7 \%)$ of them were suffering from hearing problems and using hearing aids. In relation to visual problems, $(60 \%)$ of the studied elders were suffering from visual problems and using eyeglasses, while less than one quarter $(23.3 \%)$ of them were suffering from visual problems but they did not use eyeglasses.

Regarding elders dependency in their ADLs nearlythree quarters of the studied elderly (74.1\%) were completely independent while the rest of them (25.9\%) needs assistance. 
Table 2. Distribution of the studied elders according to their medical and general health status.

\begin{tabular}{|l|c|c|}
\hline \multicolumn{1}{|c|}{ Medical and General elders' Health } & No. (240) & \% \\
\hline Have health problems & 34 & 14.2 \\
\hline No & 206 & 85.8 \\
\hline Yes & No.(206) * & \% \\
\hline Type of health problems* & 67 & 32.5 \\
\hline Heart diseases & 144 & 70 \\
\hline Hypertension & 114 & 55.3 \\
\hline DM & 89 & 43.2 \\
\hline Rheumatic & 30 & 14.6 \\
\hline Respiratory & 40 & 19.4 \\
\hline Renal & 45 & 21.8 \\
\hline GIT & No (240) & $\mathbf{\%}$ \\
\hline & & 58.3 \\
\hline Hearing problems & 140 & 16.7 \\
\hline No & 40 & 25.0 \\
\hline Use ear aid & 60 & \\
\hline Have a problem but didn't use aid & & 16.7 \\
\hline Visual Problems & 40 & 60.0 \\
\hline No & 144 & 23.3 \\
\hline Use eyeglasses & 56 & 74.1 \\
\hline Have a problem but didn't use eyeglasses & & 25.9 \\
\hline Dependency in ADL & 178 & \\
\hline Completely Independent & 62 & \\
\hline Needs assistance & & \\
\hline
\end{tabular}

* More than one answer

Table (3) portrays the living pattern and family visits of the studied elders. In relation to elders' children and grandchildren number; more than half of the studied elders had four and more children or grandchildren $(61.6 \%, 56.7 \%$ respectively).Regarding the elders' living pattern; majority of them $(84.6 \%)$ reporting that they live either with spouse, children or relatives. (43.8\%) of them confirmed that they had a role in assisting housework activities, while who were providing financial support or sharing in decision making represented $(63.7 \%, 57.1 \%$ respectively).Finally, more than one fifth of them $(22.9 \%)$ were providing care for their grandchildren.

The majority $(89.6 \%)$ of the studied elderly reported that they were visited by their children compared to one tenth $(10.4 \%)$ of them they never visited, nearly one fifth $(19.9 \%)$ of them were reported that they visited daily by their children, while less than half (46.1\%) of them stated that they visited once/week compared to $18.4 \%$ of them were visited once/month.

Regarding relatives' visits to the elders; three quarters $(75.4 \%)$ of the studied elders reported that they visited by their relatives.More than one quarter (28.2\%) of elderly were visitedby their relatives once/week, while more than one third (35.4\%) of them were visited once/month.Also, the majority of the studied elders $(82.5 \%)$ stated that they have friends. 
Table (3) Distribution of the studied elders according to their living pattern and family visits

\begin{tabular}{|c|c|c|}
\hline Elders' living pattern and family visits & No. (240) & $\%$ \\
\hline \multicolumn{3}{|l|}{ Number of children } \\
\hline None & 10 & 4.2 \\
\hline $1-3$ & 82 & 34.2 \\
\hline 4 and more & 148 & 61.6 \\
\hline \multicolumn{3}{|l|}{ Number of grandchildren } \\
\hline None & 55 & 22.9 \\
\hline $1-3$ & 49 & 20.4 \\
\hline 4and more & 136 & 56.7 \\
\hline \multicolumn{3}{|l|}{ Living alone } \\
\hline Yes & 37 & 15.4 \\
\hline No & 203 & 84.6 \\
\hline Living with & No. (203) & $\%$ \\
\hline Spouse & 82 & 40.4 \\
\hline Sons/daughters & 121 & 59.6 \\
\hline Relatives & 2 & 1.0 \\
\hline Elder roles at home & No $(240) *$ & \\
\hline Assist in housework & 105 & 43.8 \\
\hline Sharing in decision & 137 & 57.1 \\
\hline Financial support & 153 & 63.7 \\
\hline Providing care for others & 44 & 18.3 \\
\hline Providing care for grandchildren & 55 & 22.9 \\
\hline Children visits & No. (230) & $\%$ \\
\hline No & 24 & 10.4 \\
\hline Yes & 206 & 89.6 \\
\hline Number of children visits & No(206) & $\%$ \\
\hline Daily & 41 & 19.9 \\
\hline Once/week & 95 & 46.1 \\
\hline Twice/week & 28 & 13.6 \\
\hline Once/month & 38 & 18.4 \\
\hline Twice/year & 4 & 1.9 \\
\hline Relative visit & No (240) & $\%$ \\
\hline No & 59 & 24.6 \\
\hline Yes & 181 & 75.4 \\
\hline Number of relative visit & No (181) & $\%$ \\
\hline Once/week & 56 & 31 \\
\hline Twice/week & 28 & 15.5 \\
\hline Once/month & 64 & 35.4 \\
\hline Occasionally & 33 & 18.2 \\
\hline Have friends & No (240) & $\%$ \\
\hline No & 42 & 17.5 \\
\hline Yes & 198 & 82.5 \\
\hline
\end{tabular}

Table (4) reveals the elders' leisure time and hobbies. More than one fifth $(22.1 \%)$ of the studied elders were participated in volunteer activities. Less than one third (30\%) of them had hobbies. Walking, reading and handmade craft were the most commonly hobbies mentioned by the elders constituted $(43.1 \%, 26.4 \%$ and $22.2 \%$ respectively).

In relation to elders' leisure time activities, the majority of them $(85.4 \%)$ were listening to radio or watching T.V. Nearly one third $(28.3 \%)$ of the studied elders stated that they going to club to meet their friends at the leisure time, while those who practicing hobbies/ exercises, praying and doing other religious activities represented $(22.8 \%, 17.1 \%$ respectively). 
Table (4) Distribution of the studied elderly according to their hobbies and leisure time activities

\begin{tabular}{|l|c|c|}
\hline & No. (240) & \% \\
\hline Participate in volunteer activities & & 77 \\
\hline No & 53 & 22.1 \\
\hline Yes & & \\
\hline Hobbies & 168 & 70.0 \\
\hline No & 72 & 30.0 \\
\hline Yes & No(72) & \% \\
\hline Type of Hobbies & 31 & 43.1 \\
\hline Walking & 19 & 26.4 \\
\hline Reading & 6 & 8.3 \\
\hline Others (Swimming, football, traveling) & 16 & 22.2 \\
\hline Handmade craft & No. (240)* & \% \\
\hline Leisure time * & 205 & 85.4 \\
\hline Listen/watching to radio or T.V & 79 & 32.9 \\
\hline Meeting with friends in the club & 57 & 22.8 \\
\hline Practicing hobbies/exercises & 41 & 17.1 \\
\hline Praying and doing other religious activities & 13 & 5.4 \\
\hline Providing grandchildren care & & \\
\hline
\end{tabular}

*More than one answer

Table (5)shows the distribution of the studied elders according to their perceived social support score level.It was noted that more than two third $(68.8 \%)$ of the studied elders had medium perceived social support, compared to around one quarter $(24.2 \%)$ had high perceived social support and only $7.1 \%$ of them had low perceived social support score level.

Table (5) distribution of the studied elderly according to their multi-dimensionalperceived social support scale

\begin{tabular}{|l|c|c|}
\hline Multidimensional Social Perceived Support Scale (MSPSS) & No. (240) & \% \\
\hline Low perceived support (1-2.9) & 17 & 7.1 \\
\hline Medium perceived support (3-5) & 165 & 68.8 \\
\hline High perceived support (5.1-7) & 58 & 24.2 \\
\hline
\end{tabular}

Table (6)represents the distribution of the studied elders according to their moral level score. It was observed that more than half of the studied elders $(58.3 \%)$ had moderate level of morality while more than one quarter $(27.5 \%)$ of them had low level of morality, compared to $(14.2 \%)$ of them had high level ofmorality.

Table (6) distribution of the studied elderly according to their moral scale score

\begin{tabular}{|l|c|c|}
\hline MORALE SCALE & No. (240) & \% \\
\hline Low moral (1-5) & 66 & 27.5 \\
\hline Moderate moral (6-11) & 140 & 58.3 \\
\hline High moral (12-17) & 34 & 14.2 \\
\hline
\end{tabular}

Table (7)concerning the relationship between socio-demographic characteristics and the studied variables( social support and morality) this table reveals that there is a significant positive relation between elders' residence, sex, age, marital status, educational level ,working before retirement, income and multidimensional social perceived support scale where $\mathrm{P}$ value was $<0.001,<0.001,0.032,<0.001,<0.001$ and $<0.001$,respectively, whereas there is no significant relation with other socio-demographic characteristics. On the other hand a significant relation was observed between residence,sex, marital status ,educational level ,working before retirement, income and moral scale where $\mathrm{p}$ value was $<0.001,0.002,0.002,<0.001,<0.001,0.001$, and respectively.

Table (8)represents the relation between studied elders' health problems, dependency in ADLs, elders' multidimensional perceived social support scale and elders' moral scale. It was noted that there is a significant relation between hearing problems, dependency of ADLs and multidimensional perceived social support scale where $\mathrm{P}$ value was 0.001 and 0.006 respectively. On the other hand,a significant relation was observed between hearing problems, visual problems, and moral scale where $\mathrm{P}$ value was $<0.001$, and $<0.001$ respectively.

Table (9) showsthe relation between studied elders' living pattern and family visits. It was observed that there is a significant relation between number of children, grandchildren, children visits, number of children visits, relative visit, being have friends and elders' multidimensional perceived social support scale where P value was $<0.001,0.001,0.043,0.001,<0.001$, and $<0.001$ respectively. On the other hand, a significant relation was observed between number of children, grandchildren, living alone, children visits, number of children visits , relative visit, having friends and moral scale where $\mathrm{P}$ value was $<0.001,0.001,0.036,0.001,<0.001,<0.001$ and $<0.001$ respectively. 
Table (10)portrays the relation between studied elders'multidimensional perceived social support scale and moral scale. It was noted that there is a significant relation between moral scale and multi-dimension perceived social support scale where P value was 0.001 .

Table (7) Relation between socio-demographic characteristics of the studied elders, their perceived social support scale and moral scale

\begin{tabular}{|c|c|c|c|c|c|c|c|c|c|c|c|c|c|c|}
\hline \multirow{3}{*}{ Socio-demographic } & \multicolumn{6}{|c|}{$\begin{array}{l}\text { Multidimensional Social Perceived Support Scale } \\
\text { (MSPSS) }\end{array}$} & \multirow{3}{*}{$\begin{array}{l}\text { Test of } \\
\text { significance }\end{array}$} & \multicolumn{6}{|c|}{ Morale scale } & \multirow{3}{*}{$\begin{array}{l}\text { Test of } \\
\text { significance }\end{array}$} \\
\hline & \multicolumn{2}{|c|}{$\begin{array}{l}\text { Low perceived } \\
\text { support }\end{array}$} & \multicolumn{2}{|c|}{\begin{tabular}{l|} 
Medium \\
perceived support
\end{tabular}} & \multicolumn{2}{|c|}{$\begin{array}{l}\text { High perceived } \\
\text { support }\end{array}$} & & \multicolumn{2}{|c|}{ Low morale } & \multicolumn{2}{|c|}{$\begin{array}{l}\text { Moderate } \\
\text { morale }\end{array}$} & \multicolumn{2}{|c|}{ High morale } & \\
\hline & No. & $\%$ & No. & $\%$ & No. & $\%$ & & No. & $\%$ & No. & $\%$ & No. & $\%$ & \\
\hline \multicolumn{15}{|l|}{ Residence } \\
\hline Urban (Alex) & 2 & $1.7 \%$ & 66 & $55.0 \%$ & 52 & $43.3 \%$ & \multirow{2}{*}{$\begin{array}{l}\text { FET: } 53.024 \\
\text { P: }<0.001^{*}\end{array}$} & 42 & $35.0 \%$ & 44 & $36.7 \%$ & 34 & $28.3 \%$ & \multirow{2}{*}{$\begin{array}{l}\text { FET: } 67.698 \\
\mathrm{P}:<0.001^{*}\end{array}$} \\
\hline Rural (Dam) & 15 & $12.5 \%$ & 99 & $82.5 \%$ & 6 & $5.0 \%$ & & 24 & $20.0 \%$ & 96 & $80.0 \%$ & 0 & $0.0 \%$ & \\
\hline \multicolumn{15}{|l|}{ Sex } \\
\hline Male & 16 & $16.2 \%$ & 71 & $71.7 \%$ & 12 & $12.1 \%$ & \multirow{2}{*}{$\begin{array}{l}\text { FET: } 29.939 \\
\text { P: }<0.001^{*}\end{array}$} & 18 & $18.2 \%$ & 71 & $71.7 \%$ & 10 & $10.1 \%$ & \multirow{2}{*}{$\begin{array}{l}\text { FET:12.436 } \\
\text { P:0.002* }\end{array}$} \\
\hline Female & 1 & $0.7 \%$ & 94 & $66.7 \%$ & 46 & $32.6 \%$ & & 48 & $34.0 \%$ & 69 & $48.9 \%$ & 24 & $17.0 \%$ & \\
\hline \multicolumn{15}{|l|}{ Age (vears) } \\
\hline 60 to less than 75 & 11 & $5.7 \%$ & 141 & $72.7 \%$ & 42 & $21.6 \%$ & \multirow{3}{*}{$\begin{array}{l}\text { FET: } 9.646 \\
\text { P:0.032* }\end{array}$} & 50 & $25.8 \%$ & 114 & $58.8 \%$ & 30 & $15.5 \%$ & \multirow{3}{*}{$\begin{array}{l}\text { FET: } 2.747 \\
\text { P: } 0.594\end{array}$} \\
\hline 75 to less than 85 & 5 & $12.5 \%$ & 20 & $50.0 \%$ & 15 & $37.5 \%$ & & 13 & $32.5 \%$ & 23 & $57.5 \%$ & 4 & $10.0 \%$ & \\
\hline 85 and more & 1 & $16.7 \%$ & 4 & $66.7 \%$ & 1 & $16.7 \%$ & & 3 & $50.0 \%$ & 3 & $50.0 \%$ & 0 & $0.0 \%$ & \\
\hline \multicolumn{15}{|l|}{ Marital status } \\
\hline Single & 0 & $0.0 \%$ & 2 & $100.0 \%$ & 0 & $0.0 \%$ & \multirow{3}{*}{$\begin{array}{l}\text { FET: } 17.920 \\
\text { P: } 0.001^{*}\end{array}$} & 2 & $100.0 \%$ & 0 & $0.0 \%$ & 0 & $0.0 \%$ & \multirow{3}{*}{$\begin{array}{l}\text { FET:14.235 } \\
\text { P:0.002* }\end{array}$} \\
\hline Married & 16 & $12.7 \%$ & 87 & $69.0 \%$ & 23 & $18.3 \%$ & & 23 & $18.3 \%$ & 84 & $66.7 \%$ & 19 & $15.1 \%$ & \\
\hline Widow & 1 & $0.9 \%$ & 76 & $67.9 \%$ & 35 & $31.3 \%$ & & 41 & $36.6 \%$ & 56 & $50.0 \%$ & 15 & $13.4 \%$ & \\
\hline \multicolumn{15}{|l|}{ Educational level } \\
\hline Illiterate & 3 & $3.2 \%$ & 75 & $80.6 \%$ & 15 & $16.1 \%$ & \multirow{4}{*}{$\begin{array}{l}\text { FET: } 54.547 \\
\text { P: }<0.001^{*}\end{array}$} & 24 & $25.8 \%$ & 64 & $68.8 \%$ & 5 & $5.4 \%$ & \multirow{4}{*}{$\begin{array}{l}\text { FET: } 52.605 \\
\text { P: P: }<0.001^{*}\end{array}$} \\
\hline Read and write/ primary & 10 & $20 \%$ & 29 & $58 \%$ & 11 & $22 \%$ & & 15 & $30 \%$ & 30 & $60 \%$ & 5 & $10 \%$ & \\
\hline Preparatory/Secondary & 4 & $9.5 \%$ & 25 & $59.5 \%$ & 13 & $30.9 \%$ & & 10 & $23.8 \%$ & 25 & $59.5 \%$ & 7 & $16.7 \%$ & \\
\hline University & 0 & $0.0 \%$ & 36 & $65.5 \%$ & 19 & 34.5 & & 17 & $30.9 \%$ & 21 & $38.2 \%$ & 17 & $30.9 \%$ & \\
\hline \multicolumn{15}{|l|}{$\begin{array}{l}\text { Working before } \\
\text { retirement }\end{array}$} \\
\hline Professional worker & 6 & $15.8 \%$ & 32 & $84.2 \%$ & 0 & $0.0 \%$ & & 0 & $0.0 \%$ & 37 & $97.4 \%$ & 1 & $2.6 \%$ & FET: 56.165 \\
\hline Employee / Worker & 10 & $10.9 \%$ & 50 & $54.9 \%$ & 31 & $34.2 \%$ & $\begin{array}{l}\text { FET: } 62.360 \\
\text { P. }<0.001 *\end{array}$ & 28 & $30.8 \%$ & 46 & $50.5 \%$ & 17 & $18.7 \%$ & P: $<0.001^{*}$ \\
\hline Housewife & 1 & $0.9 \%$ & 83 & $74.8 \%$ & 27 & $24.3 \%$ & & 38 & $34.2 \%$ & 57 & $51.4 \%$ & 16 & $14.4 \%$ & \\
\hline Family income & & & & & & & & & & & & & & \\
\hline Not enough & 17 & $7.5 \%$ & 154 & $68.1 \%$ & 55 & $24.3 \%$ & FET: 0.592 & 62 & $27.4 \%$ & 137 & $60.6 \%$ & 27 & $11.9 \%$ & FET:13.258 \\
\hline Enough & 0 & $0.0 \%$ & 11 & $78.6 \%$ & 3 & $21.4 \%$ & P: 0.812 & 4 & $28.6 \%$ & 3 & $21.4 \%$ & 7 & $50.0 \%$ & P:0.001* \\
\hline
\end{tabular}
FET: Fisher's Exact Test
P: P value of FET
*Significant at $p$ value $\leq \mathbf{0 . 0 5}$

Table (8). Relation between studied elders' health problems,dependency in ADLs, elders' multidimensional perceived social support scale and elders' moral scale.

\begin{tabular}{|c|c|c|c|c|c|c|c|c|c|c|c|c|c|c|}
\hline & \multicolumn{6}{|c|}{$\begin{array}{l}\text { Multidimensional Social Perceived Support Scale } \\
\text { (MSPSS) }\end{array}$} & \multirow{3}{*}{$\begin{array}{l}\text { Test of } \\
\text { significance }\end{array}$} & \multicolumn{6}{|c|}{ Morale scale } & \multirow{3}{*}{$\begin{array}{c}\text { Test of } \\
\text { significance }\end{array}$} \\
\hline & \multicolumn{2}{|c|}{$\begin{array}{l}\text { Low perceived } \\
\text { support }\end{array}$} & \multicolumn{2}{|c|}{\begin{tabular}{|c|} 
Medium \\
perceived \\
support
\end{tabular}} & \multicolumn{2}{|c|}{$\begin{array}{l}\text { High perceived } \\
\text { support }\end{array}$} & & \multicolumn{2}{|c|}{ Low morale } & \multicolumn{2}{|c|}{ Moderate morale } & \multicolumn{2}{|c|}{ High morale } & \\
\hline & No. & $\%$ & No. & $\%$ & No. & $\%$ & & No. & $\%$ & No. & $\%$ & No. & $\%$ & \\
\hline \multicolumn{15}{|l|}{ Have health problems } \\
\hline No & 0 & $0.0 \%$ & 29 & $85.3 \%$ & 5 & $14.7 \%$ & \multirow{2}{*}{$\begin{array}{l}\text { FET: } 5.558 \\
\text { P: } 0.062\end{array}$} & 10 & $29.4 \%$ & 18 & $52.9 \%$ & 6 & $17.6 \%$ & \multirow{2}{*}{$\begin{array}{l}\text { FET: } 0.775 \\
\text { P:0.701 }\end{array}$} \\
\hline Yes & 17 & $8.3 \%$ & 136 & $66.0 \%$ & 53 & $25.7 \%$ & & 56 & $27.2 \%$ & 122 & $59.2 \%$ & 28 & $13.6 \%$ & \\
\hline \multicolumn{15}{|l|}{ Hearing problems } \\
\hline No & 4 & $2.9 \%$ & 96 & $68.6 \%$ & 40 & $28.6 \%$ & \multirow{3}{*}{$\begin{array}{l}\text { FET: } 16.830 \\
\text { P:0.001* }\end{array}$} & 37 & $26.4 \%$ & 77 & $55.0 \%$ & 26 & $18.6 \%$ & \multirow{3}{*}{$\begin{array}{l}\text { FET: } 36.718 \\
\mathrm{P}<0.001^{*}\end{array}$} \\
\hline Use ear aid & 7 & $17.5 \%$ & 30 & $75.0 \%$ & 3 & $7.5 \%$ & & 2 & $5.0 \%$ & 38 & $95.0 \%$ & 0 & $0.0 \%$ & \\
\hline $\begin{array}{l}\text { Have a problem but didn't } \\
\text { use aid }\end{array}$ & 6 & $10.0 \%$ & 39 & $65.0 \%$ & 15 & $25.0 \%$ & & 27 & $45.0 \%$ & 25 & $41.7 \%$ & 8 & $13.3 \%$ & \\
\hline \multicolumn{15}{|l|}{ Visual Problems } \\
\hline No & 1 & $2.5 \%$ & 28 & $70.0 \%$ & 11 & $27.5 \%$ & \multirow{3}{*}{$\begin{array}{l}\text { FET: } 4.965 \\
\text { P:0.285 }\end{array}$} & 10 & $25.0 \%$ & 22 & $55.0 \%$ & 8 & $20.0 \%$ & \multirow{3}{*}{$\begin{array}{l}\text { FET: } \\
18.503 \\
\text { P:0.001* }\end{array}$} \\
\hline Use eyeglasses & 10 & $6.9 \%$ & 104 & $72.2 \%$ & 30 & $20.8 \%$ & & 42 & $29.2 \%$ & 76 & $52.8 \%$ & 26 & $18.1 \%$ & \\
\hline $\begin{array}{l}\text { Have a problem but didn't } \\
\text { use eyeglasses }\end{array}$ & 6 & $10.7 \%$ & 33 & $58.9 \%$ & 17 & $30.4 \%$ & & 14 & $25.0 \%$ & 42 & $75.0 \%$ & 0 & $0.0 \%$ & \\
\hline \multicolumn{15}{|l|}{ Dependency in ADL } \\
\hline Completely independent & 11 & $6.2 \%$ & 138 & $77.5 \%$ & 29 & $16.3 \%$ & \multirow{2}{*}{$\begin{array}{l}\text { FET: } 32.173 \\
\text { P: } 0.006^{*}\end{array}$} & 51 & $28.7 \%$ & 97 & $54.5 \%$ & 30 & $16.9 \%$ & \multirow{2}{*}{$\begin{array}{l}\text { FET: } 7.255 \\
\text { P:0.253 }\end{array}$} \\
\hline Need assistance & 6 & $9.7 \%$ & 27 & $43.5 \%$ & 29 & $46.8 \%$ & & 15 & $24.2 \%$ & 43 & $69.4 \%$ & 4 & $6.4 \%$ & \\
\hline
\end{tabular}

FET: Fisher's Exact Test

P: $P$ value of FET

*Significant at $p$ value $\leq \mathbf{0 . 0 5}$ 
Table (9) Relation between the studied eldersliving pattern and family visits and multidimensional perceived social scale and moral scale

\begin{tabular}{|c|c|c|c|c|c|c|c|c|c|c|c|c|c|c|}
\hline \multirow[t]{3}{*}{ SOCIAL STATUS } & \multicolumn{6}{|c|}{$\begin{array}{l}\text { Multidimensional Social Perceived Support Scale } \\
\text { (MSPSS) }\end{array}$} & \multirow[t]{3}{*}{$\begin{array}{l}\text { Test of } \\
\text { significance }\end{array}$} & \multicolumn{6}{|c|}{ Morale scale } & \multirow[t]{3}{*}{$\begin{array}{l}\text { Test of } \\
\text { significance }\end{array}$} \\
\hline & \multicolumn{2}{|c|}{$\begin{array}{l}\text { Low perceived } \\
\text { support }\end{array}$} & \multicolumn{2}{|c|}{$\begin{array}{l}\text { Medium } \\
\text { perceived support }\end{array}$} & \multicolumn{2}{|c|}{$\begin{array}{l}\text { High perceived } \\
\text { support }\end{array}$} & & \multicolumn{2}{|c|}{ Low morale } & \multicolumn{2}{|c|}{$\begin{array}{l}\text { Moderate } \\
\text { morale }\end{array}$} & \multicolumn{2}{|c|}{ High morale } & \\
\hline & No. & $\%$ & No. & $\%$ & No. & $\%$ & & No. & $\%$ & No. & $\%$ & No. & $\%$ & \\
\hline \multicolumn{15}{|l|}{ Number of children } \\
\hline None & 1 & $10.0 \%$ & 7 & $70.0 \%$ & 2 & $20.0 \%$ & \multirow{3}{*}{$\begin{array}{l}\text { FET: } 38.183 \\
\mathrm{P}:<0.001^{*}\end{array}$} & 2 & $20.0 \%$ & 7 & $70.0 \%$ & 1 & $10.0 \%$ & \multirow{3}{*}{$\begin{array}{l}\text { FET }: 32.391 \\
\text { P: }<0.001^{*}\end{array}$} \\
\hline $1-3$ & 6 & $7.3 \%$ & 39 & $47.6 \%$ & 37 & $45.1 \%$ & & 25 & $30.5 \%$ & 35 & $42.7 \%$ & 22 & $26.8 \%$ & \\
\hline 4 and more & 10 & $6.7 \%$ & 119 & $80.5 \%$ & 19 & $12.8 \%$ & & 39 & $26.4 \%$ & 98 & $66.2 \%$ & 11 & $7.4 \%$ & \\
\hline \multicolumn{15}{|c|}{ Number of grandchildren } \\
\hline None & 3 & $5.5 \%$ & 40 & $72.7 \%$ & 12 & $21.8 \%$ & \multirow{3}{*}{$\begin{array}{l}\text { FET: } 32.958 \\
\mathrm{P}:<0.001^{*}\end{array}$} & 31 & $56.4 \%$ & 16 & $29.1 \%$ & 8 & $14.5 \%$ & \multirow{3}{*}{$\begin{array}{l}\text { FET }: 54.716 \\
\text { P: }<0.001^{*}\end{array}$} \\
\hline $1-3$ & 2 & $4.1 \%$ & 27 & $55.1 \%$ & 20 & $40.8 \%$ & & 16 & $32.7 \%$ & 22 & $44.9 \%$ & 11 & $22.4 \%$ & \\
\hline 4 and more & 12 & $8.8 \%$ & 98 & $72.1 \%$ & 26 & $19.1 \%$ & & 19 & $13.9 \%$ & 102 & $75 \%$ & 15 & $11.1 \%$ & \\
\hline \multicolumn{15}{|l|}{ Living alone } \\
\hline Yes & 1 & $2.7 \%$ & 22 & $59.5 \%$ & 14 & $37.8 \%$ & \multirow{2}{*}{$\begin{array}{l}\text { FET: } 4.580 \\
\text { P:0.098 }\end{array}$} & 13 & $35.1 \%$ & 15 & $40.5 \%$ & 9 & $24.3 \%$ & \multirow{2}{*}{$\begin{array}{l}\text { FET: } 6.528 \\
\text { P:0.036* }\end{array}$} \\
\hline No & 16 & $7.9 \%$ & 143 & $70.4 \%$ & 44 & $21.7 \%$ & & 53 & $26.1 \%$ & 125 & $61.6 \%$ & 25 & $12.3 \%$ & \\
\hline \multicolumn{15}{|l|}{ Children visit } \\
\hline No & 0 & $0.0 \%$ & 22 & $91.7 \%$ & 2 & $8.3 \%$ & \multirow{2}{*}{$\begin{array}{l}\text { FET: } 6.190 \\
\text { P:0.043* }\end{array}$} & 21 & $87.5 \%$ & 1 & $4.2 \%$ & 2 & $8.3 \%$ & \multirow{2}{*}{$\begin{array}{l}\text { FET }: 44.100 \\
\text { P: }<0.001^{*}\end{array}$} \\
\hline Yes & 16 & $7.8 \%$ & 136 & $66.0 \%$ & 54 & $26.2 \%$ & & 43 & $20.9 \%$ & 132 & $64.1 \%$ & 31 & $15.0 \%$ & \\
\hline \multicolumn{15}{|c|}{ Number of children visit } \\
\hline Daily & 0 & $0.0 \%$ & 30 & $73.2 \%$ & 11 & $26.8 \%$ & \multirow{5}{*}{$\begin{array}{l}\text { FET: } 24.948 \\
\text { P:0.001* }\end{array}$} & 8 & $19.5 \%$ & 20 & $48.8 \%$ & 13 & $31.7 \%$ & \multirow{5}{*}{$\begin{array}{l}\text { FET: } 24.174 \\
\text { P:0.001* }\end{array}$} \\
\hline Once/week & 9 & $9.5 \%$ & 50 & $52.6 \%$ & 36 & $37.9 \%$ & & 24 & $25.3 \%$ & 55 & $57.9 \%$ & 16 & $16.8 \%$ & \\
\hline Twice/week & 1 & $3.6 \%$ & 23 & $82.1 \%$ & 4 & $14.3 \%$ & & 4 & $14.3 \%$ & 24 & $85.7 \%$ & 0 & $0.0 \%$ & \\
\hline Once/month & 6 & $15.8 \%$ & 29 & $76.3 \%$ & 3 & $7.9 \%$ & & 5 & $13.2 \%$ & 31 & $81.6 \%$ & 2 & $5.3 \%$ & \\
\hline Twice/year & 0 & $0.0 \%$ & 4 & $100.0 \%$ & 0 & $0.0 \%$ & & 2 & $50.0 \%$ & 2 & $50.0 \%$ & 0 & $0.0 \%$ & \\
\hline \multicolumn{15}{|l|}{ Relative visit } \\
\hline No & 14 & $23.7 \%$ & 45 & $76.3 \%$ & 0 & $0.0 \%$ & FET:54.162 & 27 & $45.8 \%$ & 32 & $54.2 \%$ & 0 & $0.0 \%$ & FET: 24.434 \\
\hline Yes & 3 & $1.7 \%$ & 120 & $66.3 \%$ & 58 & $32.0 \%$ & $\mathrm{P}:<0.001^{*}$ & 39 & $21.5 \%$ & 108 & $59.7 \%$ & 34 & $18.8 \%$ & $\mathrm{P}:<0.001^{*}$ \\
\hline Have friends & & & & & & & & & & & & & & \\
\hline No & 3 & $7.1 \%$ & 38 & $90.5 \%$ & 1 & $2.4 \%$ & FET:16.849 & 9 & $21.4 \%$ & 32 & $76.2 \%$ & 1 & $2.4 \%$ & FET: 9.035 \\
\hline Yes & 14 & $7.1 \%$ & 127 & $64.1 \%$ & 57 & $28.8 \%$ & $\mathrm{P}:<0.001^{*}$ & 57 & $28.8 \%$ & 108 & $54.5 \%$ & 33 & $16.7 \%$ & P:0.010* \\
\hline
\end{tabular}

FET: Fisher's Exact Test

P: P value of FET

*Significant at $\mathbf{p}$ value $\leq \mathbf{0 . 0 5}$

Table (10) relation between the studied elders multidimensional perceived social support scale and moral scale

\begin{tabular}{|c|c|c|c|c|c|c|c|}
\hline \multirow{3}{*}{ Morale scale } & \multicolumn{6}{|c|}{ Multidimensional Social Perceived Support Scale (MSPSS) } & \multirow{3}{*}{$\begin{array}{c}\text { Test of } \\
\text { significance }\end{array}$} \\
\hline & \multicolumn{2}{|c|}{$\begin{array}{c}\text { Low perceived } \\
\text { support }\end{array}$} & \multicolumn{2}{|c|}{$\begin{array}{c}\text { Medium perceived } \\
\text { support }\end{array}$} & \multicolumn{2}{|c|}{$\begin{array}{c}\text { High perceived } \\
\text { support }\end{array}$} & \\
\hline & No. & $\%$ & No. & $\%$ & No. & $\%$ & \\
\hline Low moral (0-5) & 2 & $3.0 \%$ & 53 & $80.3 \%$ & 11 & $16.7 \%$ & \multirow{3}{*}{$\begin{array}{c}\text { FET:18.527 } \\
\text { P:0.001* }\end{array}$} \\
\hline $\begin{array}{l}\text { Moderate moral (6- } \\
\text { 11) }\end{array}$ & 15 & $10.7 \%$ & 95 & $67.9 \%$ & 30 & $21.4 \%$ & \\
\hline High moral (12-17) & 0 & $0.0 \%$ & 17 & $50.0 \%$ & 17 & $50.0 \%$ & \\
\hline
\end{tabular}

FET:Fisher's Exact Test

P: P value of FET

*Significant at $p$ value $\leq \mathbf{0 . 0 5}$

\section{Discussion}

The elderly population is now becoming of considerable concern around the world. One of the main features of the Egyptian population over the last few decades is the gradual increase in the absolute and relative numbers of elderly people. In fact, elders are more likely to face a compounding of multiple physical, psychological and social problems. ${ }^{(29,30)}$

Social support appears to play a significant role in explaining differences in subjective functioning; elderly people who are living alone or only with a spouse, seem to be at greater risk for disability problems. Those elders should receive particular attention from preventive programs in the community. ${ }^{(12,31)}$ The aim of this study was to investigate the relationship between social support and morals among community dwelling elders.

Marriage can create a sense of affection, love, and sympathy, which count as forms of social support that foster satisfaction and tranquility. ${ }^{(6)}$ Being attached to family and friends is an important element in receiving social support especially for elders, having intimate relationships with significant others provides sense of support and security as people will be available when needed. ${ }^{(32)}$

The findings of the present study revealed that the studied elders had a medium level of perceived social support; this can be interpreted as seen in Table $1 \& 3$ that more than half of the studied elders are married, living with their partner, had more than four children and grandchildren. No doubt that living with the partner, having family visits at least once weekly and having friends may enhance the elders' perceived social support. The same finding discussed by Melchior R et al (2013), ${ }^{(7)}$ who reported that a higher level of social support was independently associated with being married, living with spouse/partner or other persons e.g. daughters. Also, a study done by Moein B et al $2018^{(6)}$ revealed that marital status showed a significant relationship with social support.

The findings of the present study revealed that more than half of the studied elders have a moderate level of morality. Elders moral values based on the present study results may be enhanced due to many reasons; first of 
all, as mentioned in the present study that the studied elders are playing a significant role either in caring of their grandchildren or caring of a family member; this increases the moral value of self-worth, purpose in life and altruism in the elders. Secondly, although the majority of the studied elders reported that they did not have enough family income; their pension or children help play a role in their financial support. This may enhance the moral value of independency, status and being loved by others. This is consistent with a study done by Theodore W et al (2013) who stated that caring with others, provide the elders with a sense that they can make a positive difference in another person's life and increasing their sense of self-worth. ${ }^{(33)}$ Also, assuming any roles in the family, regardless of its type, had a significant effect on feeling of status in elders. ${ }^{(34)}$

One of the main findings of the present studythat; there is a significant relationship between social support and morality among community dwelling elders. This can be interpreted as when elderly person received social support from his family / friend and sharing decisions with them, this will automatically increase his moral value of being respected, accepted, has a status and valued by others in addition, it will enhance the value of being satisfied with life, empowerment and happiness. Taken together this will increase the elder's morality in general. This is in the same line with a study done by Beygzadeh $\mathrm{z}$ et al( 2015) who concluded that there was positive significant relationship between social support and life satisfaction with happiness. Among the domains of social support, friends and family support predicted happiness positively. Moreover, life satisfaction predicted happiness positively. ${ }^{(35)}$ Also, Chan Y(2006) $)^{(36)}$ concluded that elderly people with a larger network are happier and that social support plays a mediating role. ( social support and elders respect) other study revealed that, the ability to make decision, overcome difficulties give the elders a sense of autonomy and control over one's environment. ${ }^{(37)}$

Having a social network from family and friends is an important element in receiving social support and enhance moral value of happiness and being accepted by others. As shown in the present study that more than half of the studied elders still married, having children, grandchildren and they have at least weekly visits from their children or relatives, and the majority of the studied elders had friends. This is consistent with a study done by Bouchteli C, who Found associations between having children, grand-/ children, frequent contact with a child, living at home, , and the life satisfaction of elderly people. (38) Another studies done by Moein B et al $(2018)^{(6)}$,Beygzadeh $\mathrm{Z}(2015)^{(35)}$ suggested the presence of a significant positive relationship between the dimensions of social support and happiness; that individuals receiving more social support had higher levels of happiness.

Among the social determinants of physical and mental health in populations of elderly people, strong social networks with high levels of social support generally represent a protective factor for maintaining good health and quality of life in old age. ${ }^{(39)}$ In the present study, nearly three quarters of the studied elders reported that they are completely independent for their activities of daily living. Despite the presence of many chronic diseases, the studied elders mentioned that they go to the elders' clubs, spending time with friends and practicing hobbies and interests. All of these factors confirm the value of dependability, belonging and encourage the elders to age successfully. The friends of elderly can accompany them in social activities more frequently than can their children or other relatives. Considering the power of social support to predict happiness, social support could increase self-confidence, self-disclosure, and self-esteem in an individual, thereby helping him/her achieve goals, satisfaction with life, and, consequently, happiness. In the same line a study done by Yue Dai et al In Taiwan $(2016)^{(40)}$ found that nearly half of Tainan's elders often or always involved in social activities.

It appears from the current study that there is no statistically significant relation between the family income, having health problems and multidimensional perceived social support scale. In contrast, elders' residence, age, sex, educational level, working before retirement, number of sons/daughters had a significant relation with perceived social support. This is consistent with A study conducted by, Yue Dai et al. in Taiwan (2016) ${ }^{(40)}$ who stated that Social support was significantly correlated with age living conditions and education.

Functional independence in daily activities is a key aspect on frailty elderly quality of life. This independence is related with elderly social and leisure activities, which improves their physical and mental health and brings sense to their life.In the current study there is a significant relation between the absence of hearing problems , being completely independent for ADLs and multidimensional social support.This finding in contrast with a study done in Malysia by Sharifa P et al. $(2015)^{(33)}$ revealed that elders who had more than one chronic disease seems to protect against being dependent,whereas a good social relation from friends is associated with higher risk toward dependency.

The results of present study revealed that the minority of studied elderly had high moral level, and more than half of them had moderate moral scale. Additionally, there is a significant relation between sex, marital status, educational level, and enough family income. This is consistent with a study done by Hunter $\mathrm{W}$, ${ }^{(41)}$ who found that educational attainment to be powerful predictor of moral judgment, the effect of educational level, where $\mathrm{P}$ value $<0.001$ with greater moral judgment. Age was also a main effect $\mathrm{P}$ value $<0.001$

On the other hand Poortman A etal ${ }^{(42)}$ found that men had significantly higher mean moral scale scores than women (1.8 versus 1.7$)$ 
As mentioned before, living with family members, including spouses and children and acquiring financial and emotional attention and support, create feelings of love, care, self-esteem, and value among the elders, thus leading to a happy and healthy life, this is confirmed with the findings of the present study where a significant relation was observed between marital status ,educational level ,working before retirement, enough family income, number of grandchildren, number of sons/daughters, living alone and morals. The findings consistent with Bozo et al 2009.(43)

Finally, Considering outcomes related to having social support increasing the elders morals, a number of studies have suggested that those variables enhance a sense of happiness and can be used as a basis for treating mental disorders, increasing hope, developing psychological resistance, and reinforcing defensive power against stress. $^{(6,32,44)}$

So, community mental health nurse need to pay attention to the elderly people, provide them with necessary support, and investigate and evaluate their needs in all of life's dimensions. One such dimension is social support received from family or friends.

\section{Conclusion}

It can be concluded from the present study that, there is a significant relation between morals and multidimensions perceived social support among community dwelling elders. There is a significant relation between Sons/daughters, relative visits, number of sons/daughters visit, have friends and multidimensional perceived social support. also a significant relation was observed between sons/daughters visit, number of sons/daughters visit, relative visit, have friends and morals. Social support is of particular importance for elderly people, as later life is associated with an increased risk of exposure to various stressors such as the onset of chronic conditions and functional limitations, loss of sources of income, and loss of spouse and confidants.

\section{Recommendations: -}

Based on the results of the present study, the following recommendations are suggested: -

- Raise community awareness about the importance of social support network among elders.

- Increasing numbers of elders' clubs with sufficient financial support, this will permit elders to engage in club activities with low prices.

- Using the media to increase elders' awareness about available community-based services, especially elders' clubs and their activities.

- Family members should appreciate elders' personal achievements, and elders' life review process.

- Family members should respect the elders' decisions, as it will reflect that elders are still valued, wanted and useful. This will increase their feeling of satisfaction and enhance their morals.

- Elders must be encouraged to participate actively in the economic, political, social and cultural life of their societies.

- Country should provide different types of support to elderly population as counseling services.

- Further researches to examine the effectiveness of social support and morality among elders

\section{Limitation of the study}

Few research studies have been done with elders in the moral domain

\section{References:}

1- Engstro G. Care of the old*A matter of ethics, organization and relationships.2012 Int J Qualitative Stud Health Well-being, 7:9684

2- Central Agency for Public Mobilization and Statistics. 2010, available at: http// www.sis.gov.egyptinnumber/Egyptinfigures/ arabictables/ 45pdf. Retrieved on : March 2010.

3- Ferrni A, Ferrni R. Health in the Later Years. $5^{\text {th }}$ ed. Boston: McGraw-Hill Company, 2012.

4- Diets B. Life after Loss: A Practical guid to Renewing Your Life after Experiencing Loss. $5^{\text {th }}$ ed. Da Capo Press, 2009; $1-13$.

5- Miller C. Nursing for Wellness in Older Adults.6thed. Philadelphia: Lippincotte Williams \&Wilkins 2012; 213-215.

6- Moeini B, Barati M, FarhadianM ,Ara M. The Association between Social Support and Happiness among Elderly in Iran. Korean J Fam Med 2018; 39: 260-265.

7- Melchior R ,Chiatti C , Lamura G , Gonzales F .Social Support, Socio-Economic Status, Health and Abuseamong Older People in Seven European Countries January 2013 | Volume 8 | Issue 1 | e54856 PLOS ONE | www.plosone.org

8- Hagerty B, Williams R. The Effect of Sense of Belonging, Social Support, Conflict, and loneliness on depression. Nursing Research 1999; 48(4):215 - 221. 
9- Berkman LF, Krishna A. Social network epidemiology. In: Berkman LF, Kawachi I, Glymour MM, eds. Social epidemiology. Oxford: Oxford University Press, 2014:234-89.

10- Zunzunegui MV, Béland F, Otero A. Support from children, living arrangements, self-rated health and depressive symptoms of older people in Spain. Int J Epidemiol 2001;30:1090-9.

11- McNicholas SL. Social support and positive health practices. West J Nurs Res 2002; 5: 772-87.

12- Kuhirunyaratn P, Pongpanich S, SomrongthongR,.Support Among Elderly In Khon Kean Province, ThailandSoutheast Asian J Trop Med Public Health Vol 38 No. 5 September 2007.

13- Silverman PL, Hecht, McMillin DJ. Modeling life satisfaction among the aged: a comparison of Chinese and Americans. J Cross Cult Gerontol.2000; 4:289-305.

14- Geest S. Respect and Reciprocity: Care of Elderly People in Rural Ghana. Journal of Cross-Cultural Gerontology 2002; 17(1): 3-31.

15- DrummondJ. Respect asa Moral Emotion: A phenomolgocalApproacg. Husserl studies 2006;22(1): 127Stanford Encyclopedia of Philosophy First published Wed Apr 17, 2002; substantive revision , 2016 available at https://plato.stanford.edu > entries > morality-definition.

16- Varghese B ,Mano S.Psycho-Social Determinants of Morality: A Comprehensive Review of the Factors of Moral Information Processing International Journal of Humanities and Social Studies, Vol. 2, Issue 5, pp. $131-135,2014$

17- Shrivastava Sh. Promotion of moral values through Education. International Journal of Research in Social Sciences 2017; 7 (6): 103-108.

18- Borg C.Life satisfaction among older people with reduced self-care capacity: the relationship to social, health and financial aspects (2006) Journal of Clinical Nursing 15,607-618.

19- Dogruel L, Joecke S, Bowman N. Elderly people and morality in virtual worlds: A crosscultural analysis of elderly people's morality in interactive media. new media \& society 2012; 15(2): 276 -293.

20- Lambert $\mathrm{N}$ et al.To Matter: Sense of Belonging Enhances Meaning in Life. $\mathrm{n}$ Personality and Social Psychology Bulletin . DOI: 10.1177/0146167213499186 · Source: PubMed.2013.

21- Bélanger E, Ahmed T, Vafaei A, Curcio C, Phillips S, Zunzunegui M. Sources of social support associated with health and quality of life: a cross-sectional study among Canadian and Latin American older adults. BMJ Open 2016;6: 011503.

22- Onishi C. "Determinants of life satisfaction among Japanese elderly women attending health care and welfare service facilities," Journal of Medical Investigation, vol. 57, no. 1-2, pp. 69-80, 2010.

23- LaSala CA. Moral accountability and integrity in nursing practice. NursClin North Am. 2009 ;44(4):423-34

24- Lamb S. Cultural and Moral Values Surrounding Care and (In)Dependence in Late Life: Reflections From India in an Era of Global Modernity. 2005, Care Management Journals; 6 (2).

25- Ludwick R, Silva M. Ethics: Ethical Challenges in the Care of Elderly Persons. Online Journal of Issues in Nursing. 2003. Available at ojin.nursingworld.org > ANAPeriodicals > OJIN > Columns > EthicalChall..

26- Sahar J. Improved Health Status and Life Satisfaction among Older People following Self-Help Group Intervention in Jakarta, Current Gerontology and Geriatrics Research Volume 2017, Article ID 3879067, 7.

27- Zimet GD, Dahlem NW, Zimet SG, Farley GK. The Multidimensional Scale of Perceived Social Support. Journal of Personality Assessment 1988;52:30-41.

28- Lawton, M.P. (1975). The Philadelphia Geriatric Center Morale Scale: A revision. Journal of Gerontology, $30,85-89$

29- WHO Library Cataloguing-in-Publication Data World report on ageing and health 2015

30- Population Ageing - Egypt Report.Sweed HMiddle East Journal of Age and Ageing Volume 13, Issue 2 December 2016.

31- Tajvar M.Social support and mental health status of olderpeople: a population-based study in IranTehranAll content following this page was uploaded by 19 January 2017. ISSN: 1360-7863 (Print) 13646915 (Online) Journal homepage: http://www.tandfonline.com/loi/camh20.

32- William J, Edelstein R. Age Differences in Romantic Attachment around The World. Social Psychology and Personality Science 2013. Available at edelsteinlab.psych.Isa.Umich.edu.

33- A Prevalence Study of the Activities of Daily Living (ADL) Dependency among the Elderly in Four Districts in Selangor, Malaysia Sharifa EBW. Puteh1*, Intan MA. Bakar1, Boekhtiar Borhanuddin1, Khalib Latiff1, Rahmah M. Amin2, Rosnah Sutan1J EpidPrev Med 2015.

34- Meiner S. Gerontological Nursing. 4th ed. St. Louis, Mosby Company, 2011; 523-5.

35- BeygzadehK,Rezaei A, Khalouei Y. The relationship between social support and life satisfaction with happiness among home-dwelling older adults in Shiraz..Iranian Journal of Ageing. 2015; 10(2):172-179.

36- Chan Y, Prance L. Network size ,social support and happiness in later life :A comparative study of Beijing and Hong Kong 2006. Journal of Happiness Studies (2006) 7:87_112 _ Springer 2006 DOI 10.1007/s10902-005-1915-1.

37- Shafik H. Ego despair in old age. Review article. The 9th. International Scientific Nursing Conference, The 
2nd Scientific Association of Arab Nursing Faculties Conference "Accreditation and Nursing: Vision and Challenges", Alexandria, Egypt, 2007.

38- BouchteliC.A research rapport about the effect of social support on life satisfaction of elderly in European countries .Master thesis MSc 2017.Institute for Health Policy and Management.

39- Bélanger E,Ahmed T,Vafaei A,CurcioC. Sources of social support associated with health and quality of life: a cross-sectional study among Canadian and Latin American older adults al. BMJ Open 2016;6:e011503. doi:10.1136/bmjopen-2016-011503.

40- Yue Dai a, Zhang C, Quan Z .Social support and the self-rated health of older people A comparative study in Tainan Taiwan and Fuzhou Fujian province.Received: 3 December 2015 / Received in final form: 12 May 2016 / Accepted: 16 May 2016 http://dx.doi.org/10.1097/MD.0000000000003881

41- Hunter W,MichealW,Patt G . Aging Ripening :character\& consistency of moral judgment in young and mature and older adult.hum.dev.1983.26.277-288. All content following this page was uploaded by William Hunter on 18 December 2016.

42- Poortman A,Tilburg A, Past experiences and older adults' attitudes : a lifecourse perspective Ageing \& Society 25, 2005, 19-39. f 2005 Cambridge University Press 19 DOI: 10.1017/S0144686X04002557 Printed in the United Kingdom.

43- Bozo O,Toksabay NE, Kurum O. Activities of daily living, depression, and social support among elderly Turkish people. J Psychol.2009;143:193-205.doi: 10.3200/JRLP.143.2.193-206.

44- NovekS ,Menec V, Tran T.Social participation and its benefits. Exploring the Impacts of Senior Centres on Older Adults. Winnipeg, MB: Centre on Aging, May 2013.The Centre on Aging, University of Manitoba. 